\title{
Facile Sol-gel Synthesis of Metaloxide Nanoparticles in a Cellulose Paper Template
}

\section{Zlotski SV and Uglov VV*}

Belarusian State University of Informatics and Radioelectronics, P. Browka Str. 6, 220013 Minsk, Belarus

\begin{abstract}
Ensembles of free standing particles of titanium, zinc, copper and iron oxides of 6-109 nm in size were sol-gel synthesized with a use of a cellulose paper as a template. The calcination time as short as 60 min at $550^{\circ} \mathrm{C}$ in air was found to be sufficient for the formation of crystalline single phase $\mathrm{TiO}_{2}$ or $\mathrm{ZnO}$ nanoparticles, $\mathrm{Cu}_{2} \mathrm{O}+\mathrm{CuO}_{\text {or }} \mathrm{Fe}_{2} \mathrm{O}_{3}+\mathrm{Fe}_{3} \mathrm{O}_{4}$ nanocomposites and to burn out the organic components. The impurities initially present in the cellulose (Ca, $\mathrm{Na}$, $\mathrm{Cl}$ ) were detected in the synthesized compounds.
\end{abstract}

Keywords: Sol-gel synthesis; Titanium oxide; Zinc oxide; Copper oxides; Iron oxides; Nanoparticle; Cellulose

\section{Introduction}

Nanoparticles of metal oxides possessing semiconducting properties $\left(\mathrm{TiO}_{2}, \mathrm{ZnO}, \mathrm{Cu}_{2} \mathrm{O}, \mathrm{CuO}, \mathrm{Fe}_{2} \mathrm{O}_{3}\right.$ etc.) combined with their extended surface-to-volume ratio are of particular importance for practical applications in catalysis, solar energy harvesting, sensorics and biomedicine [1-4]. A variety of technological approaches, such as sol-gel, hydrothermal, solvothermal, anodic oxidation is used to fabricate free standing nanoparticles or nanoparticles attached to solid substrates [4]. Among them the sol-gel technology is considered to be the most suitable for perfect control of composition, morphology, size distribution and crystallinity of the nanoparticles formed. Spontaneous nucleation and subsequent crystal growth in the bulk of the sol-gel system or solid template control crystallization of the synthesized nanoparticles can be employed. The process with a nanostructured template usually needs shorter calcination times and results in more narrow size distribution.

Biomaterials and cellulose in particular are very attractive as templates providing a wide variety of shapes and sizes of the nanoparticles $[5,6]$. Moreover, they can be easily removed leaving the nanoparticles and their agglomerates free standing.

Cellulose is a biopolymer composed of repeating units of cellobiose, a dimer of glucose where each molecule of glucose is joined by a $\beta-1,4-$ glycosidic linkage $[7,8]$. In nature, the cellulose molecular chains (of about $0.3 \mathrm{~nm}$ in the lateral size) are assembled to form fibrils of 3-5 $\mathrm{nm}$ in diameter and length up to few micrometers. Their hierarchical structure is controlled by hydrogen bonding. The nanofibrils are further bundled into microfibers. Additionally, nanocrystallites as large as 50$150 \mathrm{~nm}$ and disordered $25-50 \mathrm{~nm}$ domains of cellulose can be found in the natural material. The surface of natural cellulose fibers contains abundant hydroxyl groups and nanopores thus possessing a suitable vehicle for the surface sol-gel process [9].

Cellulose fibers have already been demonstrated to perform as an efficient scaffold for assembling and immobilization of metal oxide nanoparticles synthesized by the sol-gel technique [6]. Meanwhile, a possibility to use them for fabrication of free standing ensembles of nanoparticles left upon burning off the cellulose template has been occasionally observed in a limited number of experiments: bundles of spongy nanofilaments of $\mathrm{TiO}_{2}$ and $\mathrm{ZrO}_{2}$ on a filter paper [9] and silk [10], $\mathrm{TiO}_{2}$ nanoparticles [11] and $\mathrm{ZnO} / \mathrm{SiO}_{2}$ nanocomposites [12] on a cotton fabric. Moreover, a behaviour of impurities inevitably present in the cellulose made templates was not analyzed.
In this paper we present a technology of sol-gel fabrication of free standing ensembles of metal oxide nanoparticles combining rapid calcination and burning off the cellulose paper used as a template. Its usability is illustrated with experimental results for nanoparticles of $\mathrm{TiO}_{2}, \mathrm{ZnO}, \mathrm{CuO}, \mathrm{Fe}_{2} \mathrm{O}_{3}$. A fate of the impurities such as calcium $(\mathrm{Ca})$, sodium $(\mathrm{Na})$, chlorine $(\mathrm{Cl})$ detected in the template was traced.

\section{Experimental Section}

Commercial cellulose filter paper as thick as $0.32 \mathrm{~mm}$ was used as a template for in situ nanostructuring of metal oxides during their sol-gel synthesis. The templates cut from this paper were $10 \times 25 \mathrm{~mm}^{2}$ in size. All chemicals used in the experiments were analytical grade compounds. The list of precursors included titanium tetraisopropoxide $\left(\mathrm{C}_{12} \mathrm{H}_{28} \mathrm{O}_{4} \mathrm{Ti}\right)$ for $\mathrm{TiO}_{2}$, zinc acetate anhydrate $\left(\left(\mathrm{CH}_{3} \mathrm{COO}\right)_{2} \mathrm{Zn}\right)$ for $\mathrm{ZnO}$, copper(II) nitrate $\left(\mathrm{Cu}\left(\mathrm{NO}_{3}\right)_{2}\right)$ for $\mathrm{CuO}$, iron(II) nitrate $\left(\mathrm{Fe}\left(\mathrm{NO}_{3}\right)_{2}\right)$ for $\mathrm{Fe}_{2} \mathrm{O}_{3}$. They were added to n-butanol up to concentrations of $0.2 \mathrm{mmol} / \mathrm{l}$. The composed sols were mechanically stirred at room temperature for $10 \mathrm{~min}$ and then left undisturbed for $24 \mathrm{~h}$ ageing. The templates were dipped in the sols for $30 \mathrm{~s}$ and dried in air at $200^{\circ} \mathrm{C}$ for $5 \mathrm{~min}$. Then they were annealed in air at $550^{\circ} \mathrm{C}$ for $60 \mathrm{~min}$ to initiate calcination combined with burning off the original cellulose paper. The final product had a form of fragile $0.5-5 \mathrm{~mm}$ flakes which were subsequently analyzed with scanning electron microscopy (SEM), energy-dispersive X-ray (EDX) spectroscopy and X-ray diffraction (XRD, $\lambda=1,54179 \mathrm{~nm}$ ) techniques. The XRD library [13] was used to interpret the corresponding experimental patterns. The size of the crystalline grains of the materials formed was extracted from SEM images and calculated from the XRD patterns according to the Scherrer equation.

\section{Results and Discussion}

The SEM image presented in Figure 1 demonstrates that the

*Corresponding author: Uglov VV, Belarusian State University of Informatics and Radioelectronics, P. Browka Str. 6, 220013 Minsk, Belarus, Tel: 375172938815; E-mail: filippova.tatyana.a@gmail.com

Received November 01, 2017; Accepted November 07, 2017; Published November 13, 2017

Citation: Zlotski SV, Uglov VV (2017) Facile Sol-gel Synthesis of Metaloxide Nanoparticles in a Cellulose Paper Template. J Nanomedic Nanotechnol S8: 002 doi:10.4172/2157-7439.S8-002

Copyright: ( 2017 Zlotski SV, et al. This is an open-access article distributed under the terms of the Creative Commons Attribution License, which permits unrestricted use, distribution, and reproduction in any medium, provided the original author and source are credited. 
Citation: Zlotski SV, Uglov VV (2017) Facile Sol-gel Synthesis of Metaloxide Nanoparticles in a Cellulose Paper Template. J Nanomedic Nanotechnol S8: 002. doi:10.4172/2157-7439.S8-002

Page 2 of 3

original cellulose paper is composed of randomly oriented belt-like up to few millimeters long fibers. Their lateral size varies from $1 \mu \mathrm{m}$ to $30 \mu \mathrm{m}$. The fibers were found to be perforated with 10-50 $\mathrm{nm}$ pores. The EDX spectroscopy showed them to contain along with the main elements (carbon 44.14 at.\% and oxygen 55.62 at.\%) also calcium 0.12 at.\%, sodium 0.07 at.\% and chlorine 0.05 at. $\%$.

Annealing of the sol impregnated cellulose templates at $550^{\circ} \mathrm{C}$ in air resulted in burning off the cellulose fibers leaving flakes of the synthesized material. The flakes had colors corresponding to the oxides expected to be formed: white for $\mathrm{TiO}_{2}$ and $\mathrm{ZnO}$, black for $\mathrm{CuO}$, redbrown for $\mathrm{Fe}_{2} \mathrm{O}_{3}$. Typical structure of the flakes is illustrated in Figure 2 with an example when $\mathrm{ZnO}$ precursor was used.

The flakes have a coral structure formed by agglomerated 30-50 nm grains. A certain dense arrangement of the grains along some directions and large irregular pores (up to micrometers in cross-section) between the agglomerated blocks testify the cellulose fibers to provide seeding points for nucleation of the grains. In general, the flakes reproduce the morphological information of the original cellulose paper at the nanometer and micrometer scales. That falls in common with previously observed replication of the cellulose morphology by sol-gel derived $\mathrm{TiO}_{2}$ nanotubes [9].

The XRD analysis performed demonstrated the grains to be of a crystalline nature with the compositions and crystalline structures corresponding to the expected oxides. Figure 3 presents examples of the recorded XRD patterns.

The crystallites of the oxides formed have no dominating orientations. Their size is in the range of 6-109 $\mathrm{nm}$ with the main fraction of the $30-50 \mathrm{~nm}$ grains also identified with $\mathrm{SEM}^{\mathrm{TiO}} \mathrm{T}_{2}$ and $\mathrm{ZnO}$

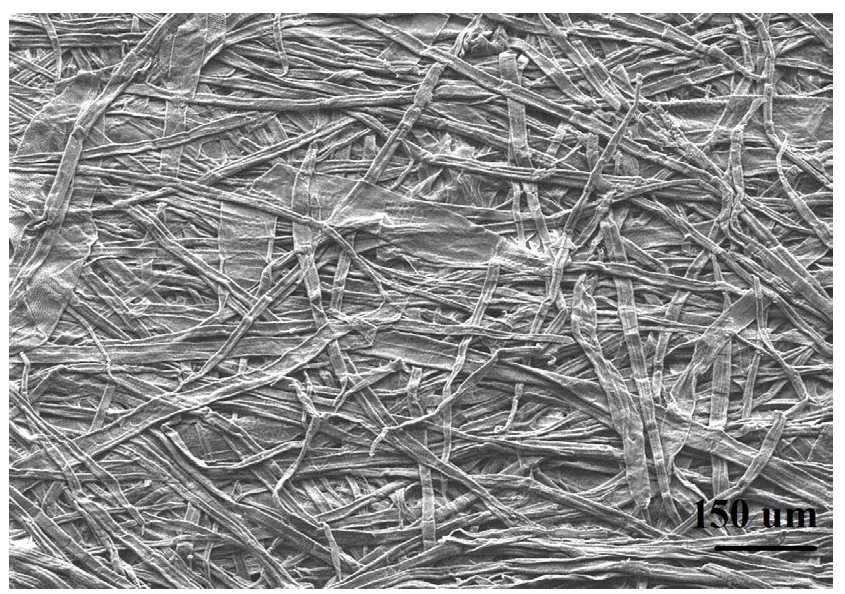

Figure 1: SEM image of the cellulose filter paper used as a template for sol-gel synthesis of metal oxide nanoparticles.

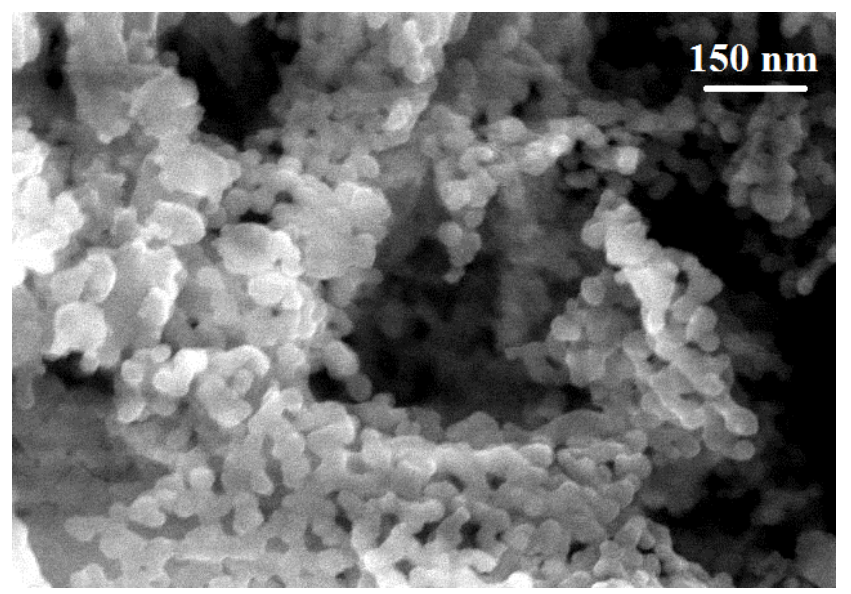

Figure 2: SEM image of $\mathrm{ZnO}$ sol-gel synthesized in the cellulose paper template.

\begin{tabular}{|c|c|c|c|c|c|c|c|}
\hline \multirow[t]{2}{*}{ Oxide Characteristic } & \multirow[t]{2}{*}{$\mathrm{TiO}_{2}$} & \multirow[t]{2}{*}{$\mathrm{ZnO}$} & \multicolumn{3}{|c|}{ Cu oxides } & \multicolumn{2}{|c|}{ Fe oxides } \\
\hline & & & $\mathrm{Cu}_{2} \mathrm{O}$ & $\mathrm{CuO}$ & $\mathrm{CuO}$ & $\mathrm{Fe}_{2} \mathrm{O}_{3}$ & $\mathrm{Fe}_{3} \mathrm{O}_{4}$ \\
\hline Phase & Anatase & Zincite & Cuprite & Tenorite & Copper oxide & Hematite & iron (II,III) oxide \\
\hline Crystal structure & Tetragonal & Hexagonal & Cubic & Monoclinic & Monoclinic & Trigonal & Monoclinic \\
\hline Size of the crystallites, nm & $6-27$ & $10-109$ & $24-53$ & $28-73$ & $23-72$ & $24-76$ & $30-76$ \\
\hline Dominating crystallites, $\mathrm{nm}$ & 19 & $20-21$ & 34 & $25-31$ & 33 & $31-35$ & 31 \\
\hline
\end{tabular}

Table 1: XRD characteristics of the oxides sol-gel synthesized in the cellulose paper template. 

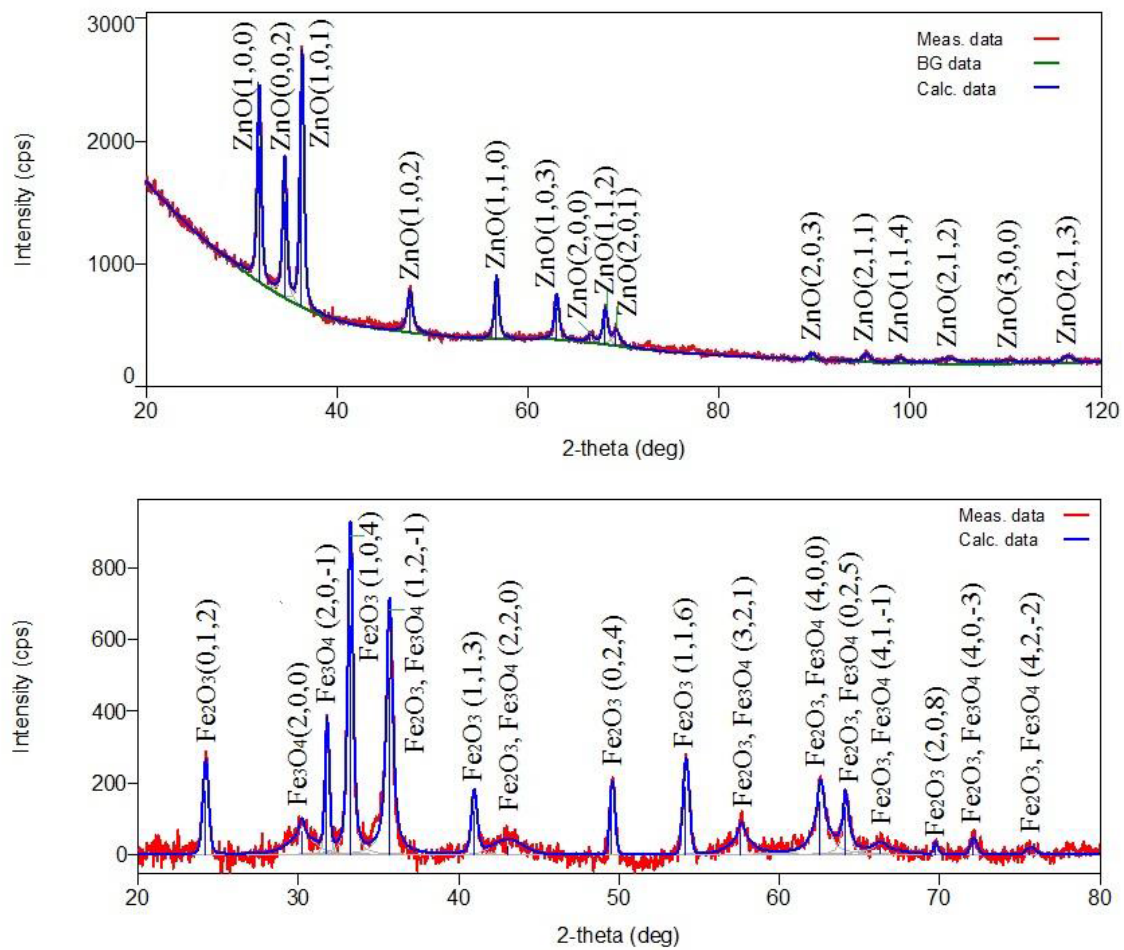

Figure 3: XRD patterns of the ensembles formed by nanoparticles of zinc (a) and iron (b) oxides sol-gel synthesized in the cellulose paper template

were found to be synthesized as single composition oxides. Remarkably that $\mathrm{TiO}_{2}$ obeys only anatase crystal structure. No other crystal phases of this oxide (rutile, brukit) were identified. In contrast, copper and iron oxides are represented by the mixtures of two compounds: $\mathrm{CuO}$ (Tenorite $-96.8 \%$, Copper oxide $-3.2 \%)+\mathrm{Cu}_{2} \mathrm{O}(<0.1 \%)$ and $\mathrm{Fe}_{2} \mathrm{O}_{3}(14.6 \%)+\mathrm{Fe}_{3} \mathrm{O}_{4}(85.4 \%)$, respectively. They have quite different crystal structures. Other characteristics extracted from the XRD patterns are summarized in Table 1.

While the size of crystalline grains varies in a wide nanometer range, each oxide has a dominating dimension. These dominating dimensions correlate with the size of the pores in the template.

No crystal phases of compounds including carbon and impurities from the cellulose template were detected. Meanwhile, EDX spectroscopy has shown them to be at concentrations comparable with those in the template material. Presumably they are adsorbed at the surface of the crystallized metal oxides.

\section{Conclusion}

Sol-gel synthesis of $\mathrm{TiO}_{2}, \mathrm{ZnO}, \mathrm{Cu}_{2} \mathrm{O}+\mathrm{CuO}, \mathrm{Fe}_{2} \mathrm{O}_{3}+\mathrm{Fe}_{3} \mathrm{O}_{4}$ in the cellulose paper template has been demonstrated to be an efficient facile route providing formation of free standing ensembles of metal oxide nanoparticles. Single phase and nanostructured compositions of the oxides may be fabricated. Type and concentration of impurities in the synthesized materials can be regulated by their content in the cellulose template. The proposed and tested technique looks promising for fabrication of nanocomposites on the basis of metal oxides.

\section{Acknowledgements}

This work was financially supported by the Belarusian National Program "Convergence" (project 3.2.04). The authors are grateful to D. V. Zhigulin for the SEM and EDX spectroscopy of the samples.

\section{References}

1. Tong $\mathrm{H}$, Ouyang $\mathrm{S}, \mathrm{Bi} \mathrm{Y}$, Umezawa $\mathrm{N}$, Oshikiri $\mathrm{M}$, et al. (2012) Nanophotocatalytic materials: possibilities and challenges. Adv Mater. 24: 229-251.

2. Gu X, Li C, Yuan S, Ma M, Qiang Y, et al. (2016) ZnO based eterojunctions and their application in environmental photocatalysis. Nanotechnology 27: 402001.

3. Salata O (2004) Applications of nanoparticles in biology and medicine. Journal of Nanobiotechnology 2: 3.

4. Li Y, Yang X, Feng Y, Yuan Z, Su B (2012) One-Dimensional Meta Oxide Nanotubes, Nanowires, Nanoribbons, and Nanorods: Synthesis Characterizations, Properties and Applications. Critical Reviews in Solid State and Materials Sciences 37: 1-74.

5. Kaushik M, Moores A (2016) Review: Nanocelluloses as versatile supports for metal nanoparticles and their applications in catalysis. Green Chem 18 622-637.

6. Tian H, He J (2016) Cellulose as a Scaffold for Self-Assembly: From Basic Research to Real Applications. Langmuir 32: 12269-12282.

7. loelovich $M(2008)$ Cellulose as a nanostructured polymer: a short review. BioResources 3: 1403-1418.

8. Klemm D, Kramer F, Moritz S, Lindström T, Ankerfors M, et al. (2011) Nanocelluloses: A New Family of Nature-Based Materials. Wiley online library 50: $5438-5466$.

9. Huang J, Kunitake T (2003) Nano-Precision Replication of Natural Cellulosic Substances by Metal Oxides. J Am Chem Soc 125: 11834-11835.

10. He J, Kunitake T (2004) Preparation and Thermal Stability of Gold Nanoparticles in Silk-Templated Porous Filaments of Titania and Zirconia. Chem Mater 16: 2656-2661.

11. El-Naggar T, Shaheen S, Zaghloul M, El Rafie M, Hebeish A (2016) Antibacterial Activities and UV Protection of the in Situ Synthesized Titanium Oxide Nanoparticles on Cotton Fabrics. Ind Eng Chem Res 55: 2661-2668.

12. Barani $\mathrm{H}$ (2014) Preparation of antibacterial coating based on in situ synthesis of $\mathrm{ZnO} / \mathrm{SiO}_{2}$ hybrid nanocomposite on cotton fabric. Appl Surf Sci 320: 429-434.

13. https://www.ccdc.cam.ac.uk/ 